\title{
Effect of glucocorticoids on the function of microvascular endothelial cells in the human femoral head bone
}

\author{
Yufeng $\mathrm{Lu}^{1, B-D, F}$, Qingsheng $\mathrm{Yu}^{2, \mathrm{C}}$, Wanshou Gu0 ${ }^{3, \mathrm{~A}}$, Yangquan Hao ${ }^{1, \mathrm{E}, \mathrm{F}}$, Wei Sun ${ }^{3, \mathrm{C}}$, Liming Cheng ${ }^{3, B}$ \\ ${ }^{1}$ Department of Joint Surgery, Osteonecrosis and Joint Reconstruction Ward, Honghui Hospital, Xi'an Jiaotong University, China \\ ${ }^{2}$ Beijing Key Laboratory of Arthritic and Rheumatic Diseases, China-Japan Friendship Hospital, China \\ ${ }^{3}$ Department of Orthopedic Surgery, Centre for Osteonecrosis and Joint-Preserving \& Reconstruction, Beijing Key Laboratory of Arthritic and Rheumatic Diseases, China-Japan \\ Friendship Hospital, China
}

A - research concept and design; $\mathrm{B}$ - collection and/or assembly of data; $\mathrm{C}$ - data analysis and interpretation;

$D$ - writing the article; $E$ - critical revision of the article; $F$ - final approval of the article

\section{Address for correspondence \\ Wanshou Guo}

E-mail: guowanshou123@126.com

\section{Funding sources}

This work was funded by a grant from National Natural Science Foundation of China (grant No. 81273972), and Xi'an Science and Technology Bureau project (grant No. J201903058).

Conflict of interest

None declared

Received on November 8, 2018

Reviewed on November 13, 2018

Accepted on September 25, 2019

Published online on March 27, 2020

Cite as

Lu Y, Yu Q, Guo W, Hao Y, Sun W, Cheng L. Effect of glucocorticoids on the function of microvascular endothelial cells in the human femoral head bone. Adv Clin Exp Med. 2020;29(3):345-353. doi:10.17219/acem/112602

DOI

10.17219/acem/112602

\section{Copyright}

Copyright by Author(s)

This is an article distributed under the terms of the

Creative Commons Attribution 3.0 Unported (CC BY 3.0)

(https://creativecommons.org/licenses/by/3.0/)

\begin{abstract}
Background. The pathogenesis of glucocorticoid (GC)-induced osteonecrosis (ON) of the femoral head remains unclear. Recent research has suggested that it is closely associated with injured bone microvascular endothelial cells (BMECS). However, few studies have used BMECs to perform research pertaining ON of the femoral head.

Objectives. The objective of this study was to investigate the functional changes of BMECs treated with a GC and to detect the changes in related genes using microarrays.

Material and methods. Cells were isolated using an enzymatic method and identified with EC markers, such as von Willebrand factor (VWF), CD31 and vascular endothelial cadherin (VE-cadherin). Bone microvascular endothelial cells were treated with $0.1 \mathrm{mg} / \mathrm{mL}$ and $0.3 \mathrm{mg} / \mathrm{mL}$ of hydrocortisone to establish a GCdamaged model of BMECS. The mRNA microarrays were used to detect the differential expression profiles between BMECs with and without GC damage.

Results. Primary cells appeared as having a cobblestone-like morphology. Immunofluorescence staining revealed that the cells were 100\% positive for VWF and CD31, and near 100\% positive for VE-cadherin. It also confirmed that the cells were BMECs. Bone microvascular endothelial cells treated with $0.1 \mathrm{mg} / \mathrm{mL}$ of hydrocortisone showed shrinkage, and those treated with $0.3 \mathrm{mg} / \mathrm{mL}$ of hydrocortisone mostly showed apoptosis. The mRNA microarray showed that genes associated with endothelial cells, such as endothelin 1 (ET-1) receptor, angiotensin II (All) receptor, intercellular achesion molecule 1 (ICAM-1), and plasminogen activator inhibitor 1 (PAl-1), were upregulated, and genes associated with endothelial nitric oxide synthase (eNOS), endothelin 1 (ET-1), prostaglandin $\mathrm{I}_{2}\left(\mathrm{PGI}_{2}\right)$ synthase, $\mathrm{PG} \mathrm{I}_{2}$ receptor, vascular endothelial growth factor (VEGF), prostaglandin E (PGE) synthase, and PGE receptor were downregulated. The results of quantitative polymerase chain reaction (qPCR) validation were consistent with the findings of $m R N A$ microarrays.
\end{abstract}

Conclusions. Glucocorticoids promoted BMECs to express vasoconstrictors and procoagulant factors and related receptors, and decreased the expression of vasodilators and their receptors.

Key words: glucocorticoids, microarray analysis, cell culture techniques, microvascular endothelial cells, real-time polymerase chain reaction 


\section{Introduction}

Non-traumatic avascular necrosis of the femoral head is a refractory hip joint lesion. The causes of the disease are the use of glucocorticoids, ${ }^{1}$ alcoholism, ${ }^{2}$ decompression sickness, ${ }^{3}$ sickle cell anemia, ${ }^{4}$ and idiopathic causes. ${ }^{5}$ However, glucocorticoid (GC)-induced osteonecrosis (ON) of the femoral head $(\mathrm{ONFH})$ accounts for a large proportion of this occurrence, ${ }^{6-9}$ primarily occurs in young individuals, and shows characteristics of short course and early collapse. In addition, middle-aged and older people can have ONFH. However, the pathogenesis of steroid-induced ONFH is still not very clear. Presently, osteoblast apoptosis, ${ }^{10,11}$ lipid metabolism abnormality, ${ }^{12}$ intravascular coagulation, ${ }^{13}$ and vascular endothelial dysfunction ${ }^{14}$ are hypothesized as factors causing ONFH. However, a study indicated that the pathogenesis of steroid-induced ONFH was the result of a comprehensive effect of multiple factors. ${ }^{15}$ Recently, more and more authors believe that steroid-induced ONFH is closely related to the damage to bone microvascular endothelial cells (BMECs) in the femoral head. Vogt and SchmidSchönbein ${ }^{16}$ found that a large dose of dexamethasone could induce apoptosis of mesenteric microvascular endothelial cells. Li et al. ${ }^{17}$ pointed out that endothelial cell injury, an increase of local procoagulant factors and low fibrinolysis could be responsible for GC-induced ON. Yang et al. ${ }^{18}$ found that reactive oxygen species (ROS) concentration was higher in the femoral head BMECs than in the control group; there was a positive correlation between ROS concentration and GC levels, suggesting that high GC levels lead to increased ROS concentration in endothelial cells and cause irreversible damage to cells, eventually leading to cell death. The above studies showed that glucocorticoids damaged the microvascular endothelial cells, leading to endothelial dysfunction, apoptosis and death. However, only a few studies have been reported on the kind of changes that occur after BMECs injury. Endothelial cells have endocrine functions ${ }^{19}$; they can synthesize and secrete various bioactive substances and play an important role in regulating local blood flow and body fluid balance. Their functions involve vasoconstriction, coagulation and fibrinolysis, angiogenesis and cell proliferation, oxidative stress, cell adhesion, and inflammatory mediation, which include endothelial nitric oxide synthase (eNOS), prostaglandin $\mathrm{I}_{2}\left(\mathrm{PGI}_{2}\right)$, endothelin 1 (ET-1), intercellular adhesion molecule 1 (ICAM-1), vascular cell adhesion molecule 1 (VCAM-1), tissue plasminogen activator (t-PA), plasminogen activator inhibitor 1 (PAI-1), vascular endothelial growth factor $(V E G F)$, von Willebrand factor (vWF), fibroblast growth factor (FGF), interleukin 1 (IL-1), and IL-6. In addition, there are some vasoactive substances in the blood, such as angiotensin II (AII); although endothelial cells cannot be synthesized, they still play a role in regulating vasoconstriction, coagulation and fibrinolysis by binding with endothelial cell receptors.

Do BMECs in the femoral head have the same functions as other endothelial cells? It was considered that steroid-induced
ONFH was characterized by systemic coagulation and fibrinolytic dysfunction. For example, van Veldhuizen et al. ${ }^{20}$ and Glueck et al. ${ }^{21}$ found that PAI-1 expression increased and t-PA expression decreased in patients with $\mathrm{ON}$. Asano et al. ${ }^{22}$ found the polymorphism of PAI-1 gene in patients with ONFH after renal transplantation. They showed that the vasoactive substances secreted by the endothelial cells of necrotic femoral head had changed. Therefore, it can be speculated that glucocorticoids may cause severe damage to BMECs. However, the abovementioned research was relatively rare, and the cells used were either from animal models or from other organ-derived endothelial cells. Our study was based on a few previous experiments ${ }^{18,23,24}$ and involved hydrocortisone being used on in vitro-cultured human femoral head BMECs. Herein, we established a GC-damaged model of BMECs and detected differentially expressed genes using high-throughput expression chips and real-time quantitative polymerase chain reaction (RT-qPCR) to study function change of the cytokine and the related receptor of GC-induced human femoral head damage model of BMECs.

\section{Material and methods}

\section{Ethics statement and patients}

The protocol described herein was approved by the ethics committee of the China-Japan Friendship Hospital, Beijing, China, and is in compliance with the tenets

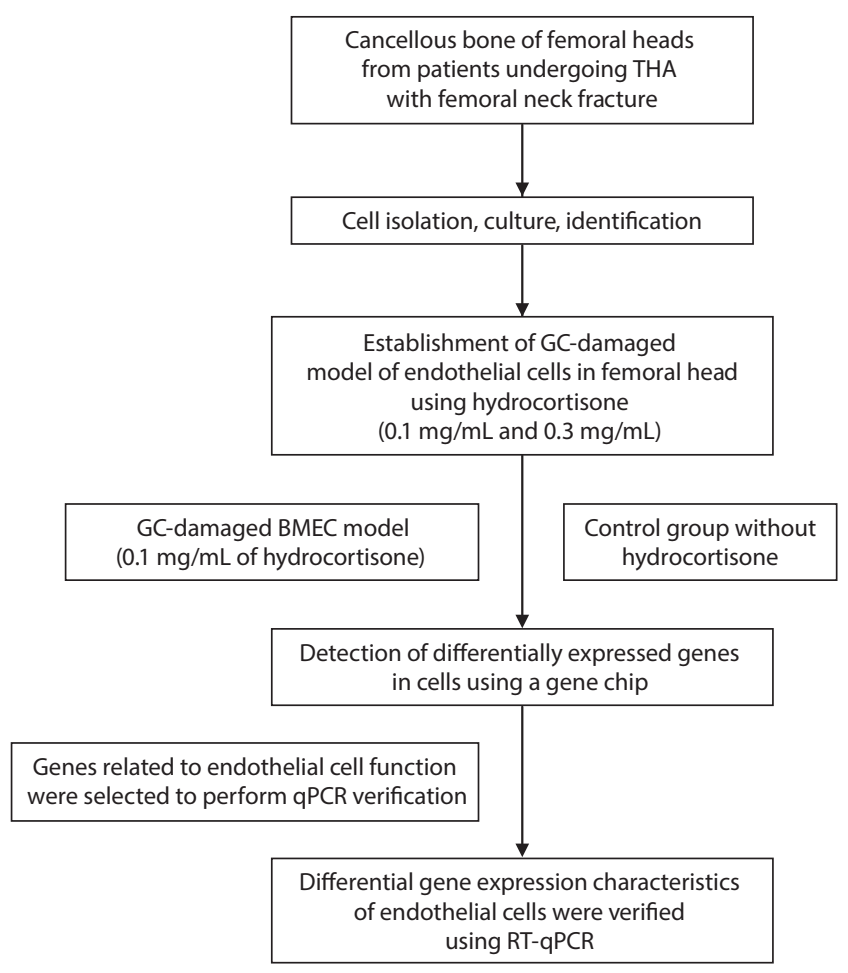

Fig. 1. Flow diagram illustrating cell culture and gene chip experiments

THA - total hip arthroplasty; PCR - polymerase chain reaction; RT-qPCR - real-time quantitative PCR; BMEC - bone microvascular endothelial cell; GC - glucocorticoid 
of the Declaration of Helsinki on ethical principles for medical research involving human subjects (Institutional Clinical Trials Register Number is 2014-34). All participants provided written informed consent. All patients were enrolled at the China-Japan Friendship Hospital between October 1, 2013 and February 28, 2014. Patients with femoral neck fracture requiring hip arthroplasty were included. Exclusion criteria were the following: patients with ONFH, ankylosing spondylitis, rheumatoid arthritis, other inflammatory joint diseases involving the hip joint, hemophilic arthropathy, hip tuberculosis, pyogenic infection, perihip tumors, and systemic diseases (e.g., diabetes). A total of 9 patients met the above criteria, including 1 man and 8 women (average age: 79.1 years, age range: $62-92$ years). Our entire experimental process was shown in Fig. 1.

\section{Isolation of human femoral head bone microvascular endothelial cells}

The femoral heads were obtained from patients with femoral neck fractures who underwent total hip arthroplasty. The soft tissue and cartilage of the femoral heads were removed, and the cancellous bone was bitten into granule with a rongeur under aseptic conditions in the operating room (Fig. 2A). The cancellous bone was placed into a centrifugal tube containing $30 \mathrm{~mL}$ of heparinized, serumfree Dulbecco's modified Eagle's medium (DMEM; Hyclone Laboratories, South Logan, USA) and carefully transferred to the laboratory. Samples were shaken repeatedly for 3-5 min and the medium was removed. Then, the cells were transferred into a new centrifugal tube and washed several times with Hanks' balanced salt solution (HBSS; Gibco, Carlsbad, USA) until the rinse was clear. Then, the rinse fluid was removed from the bone, and DMEM containing 1.5-2\% collagenase type I (Solarbio, Beijing, China) was added to the bone tissue, with the liquid level slightly higher than that of bone granule; then, the sample was incubated in a water bath for $30 \mathrm{~min}$ at $37^{\circ} \mathrm{C}$. Thereafter, $0.25 \%$ trypsin and $0.53 \mathrm{mM}$ ethylenediaminetetraacetic acid (EDTA; Solarbio) were added, and incubation was done in a water bath at $37^{\circ} \mathrm{C}$ for $5 \mathrm{~min}$. Immediately, these digestive juices were transferred to a 70-micrometer cell strainer and then placed on a 50-milliliter Falcon tube. Then, the suspension was subjected to centrifugation at $200 \times$ g for $10 \mathrm{~min}$ and the resulting pellet was collected. The pellet was re-suspended in M199 culture medium (Hyclone) supplemented with 20\% fetal bovine serum (FBS; Gibco), 10 ng/mL of VEGF (Sino Biological Inc., Beijing, China), $100 \mathrm{ug} / \mathrm{mL}$ of streptomycin (Solarbio), $100 \mathrm{U} / \mathrm{mL}$ of penicillin (Solarbio), and $40 \mathrm{U} / \mathrm{mL}$ of heparin (Xinbai Pharmaceutical, Nanjing, China) in a Petri dish pre-coated with gelatin $2 \%$ (Sigma-Aldrich, St. Louis, USA). The cells were incubated at $37^{\circ} \mathrm{C}$ under $5 \% \mathrm{CO}_{2}$ conditions.

After $24 \mathrm{~h}$ of incubation, the cells started showing attachment to the dish. Unattached blood cells and debris were removed by changing the $20 \%$ FBS serum-supplemented medium. Medium change was performed every 3-5 days according to the color of the medium. Phase-contrast microscope (Olympus IX71; Olympus Corp., Tokyo, Japan) was used to monitor cell growth. When about $80 \%$ confluence was reached (about 7-10 days after primary culture), the cells were treated with $1 \mathrm{~mL} 0.25 \%$ trypsin and $0.53 \%$ EDTA for 3 min for harvesting. Trypsin was carefully aspirated; the cells were subjected to centrifugation at $200 \times \mathrm{g}$ for $10 \mathrm{~min}$. Then, the pellet was resuspended with $10 \mathrm{~mL}$ of M199 culture medium (Hyclone). The suspended cells were split in 1:2 ratio and cultured using gelatin-coated plates; then, they were maintained in M199 culture medium as described above.

\section{Characterization of endothelial cells}

Cells from 2 or 3 generations of patients were characterized using the endothelial cell characterization kit (Bioss Antibodies, Woburn, USA) according to manufacturer instructions. The cells were grown on a glass coverslip, and the coverslip was washed with phosphate-buffered saline (PBS) 3 times for $5 \mathrm{~min}$, and then the cells were fixed with $4 \%$ paraformaldehyde for $30 \mathrm{~min}$ at room temperature. Next, the cells were washed $(3 \times$ PBS) for $5 \mathrm{~min}$ and incubated at room temperature for $1 \mathrm{~h}$ with blocking buffer comprising 0.05\% Triton X-100 (Solarbio) and 10\% FBS in $3 \times$ PBS. The primary antibody (rabbit anti-human IgG) (Bioss Antibodies) was diluted with a working concentration of the blocking buffer; next, the cells were incubated with the primary antibodies vWF, CD31 and vascular endothelial cadherin (VE-cadherin; Bioss Antibodies) overnight at $4^{\circ} \mathrm{C}$. Then, secondary antibodies (goat anti-rabbit IgG; Bioss Antibodies) labeled with fluorescein isothiocyanate were added, along with Hoechst33342 stain solution (Sigma-Aldrich), and the cells were incubated for $90 \mathrm{~min}$. Next, the cells were fixed on adhesive slides with an anti-fluorescence attenuating agent. Homologous antibodies were used as negative controls. Finally, the cells were washed with $1 \times$ PBS and analyzed using a fluorescent microscope (Olympus Corp.).

\section{Establishment of glucocorticoid-damaged BMEC model}

The $2^{\text {nd }}$ or $3^{\text {rd }}$ generation cells of 8 patients (the cells from a 92-year-old woman had poor cell growth and were excluded) were selected to establish GC-damaged BMEC model. When the cells reached about $80 \%$ confluence, hydrocortisone (Tianjin Kingyork, Tianjin, China) was introduced to the culture medium of the experimental groups, and the final concentration was $0.1 \mathrm{mg} / \mathrm{mL}$ and $0.3 \mathrm{mg} / \mathrm{mL}$. Hydrocortisone was not added to the control group. The cells were monitored under an inverted microscope (Olympus Corp.) after being cultured for $6 \mathrm{~h}$, $12 \mathrm{~h}, 18 \mathrm{~h}$, and $24 \mathrm{~h}$ after drug administration. After $24 \mathrm{~h}$, the total RNAs of cell samples were extracted with TRIzol reagent (Invitrogen, Germany). 


\section{Detection and data analysis of gene chips}

Total RNA was isolated using the TRIzol reagent according to the manufacturer's protocol. After the qualitative and quantitative detection of mRNA, qualified crystal core $^{\circledR}$ mRNA expression profiling chip (CapitalBio, Beijing, China) was used for detection. Specific experimental steps refer to the biological experimental scheme of CapitalBio Corporation (http://cn.capitalbio.com). The hybridization pictures were acquired and analyzed using Agilent Feature Extraction software v. 10.7 (Agilent Technologies, Santa Clara, USA). The data were normalized and the differences between the groups were analyzed using Agilent GeneSpring software (Agilent Technologies).

\section{Quantitative real-time PCR assays}

Differentially expressed genes associated with endothelial cell function were selected for quantitative polymerase chain reaction (qPCR) verification. After the cells from the experimental group with $0.1 \mathrm{mg} / \mathrm{mL}$ of hydrocortisone and those from the control group were cultured for $24 \mathrm{~h}$, TRIzol reagent was used to extract total RNA from the cells. Thereafter, reverse transcription into cDNA was performed according to the manufacturer's protocol. The PCR amplification was done in 96-well plates. The conditions of the PCR reaction were the following: $95^{\circ} \mathrm{C}$ for $10 \mathrm{~min}$, and amplification for 40 cycles at $95^{\circ} \mathrm{C}$ for $15 \mathrm{~s}$ and $60^{\circ} \mathrm{C}$ for $60 \mathrm{~s}$. In addition, a melting curve step was performed at $95^{\circ} \mathrm{C}$ for $15 \mathrm{~s}$ and at $60^{\circ} \mathrm{C}$ for $1 \mathrm{~min}$, and then the temperature was increased at a rate of $0.11^{\circ} \mathrm{C} / \mathrm{s}$ until reaching $95^{\circ} \mathrm{C}$ to measure fluorescence signals. The experiment was repeated 3 times to get the average value.

\section{Statistics}

The data was represented as mean \pm standard deviation (SD) for $\mathrm{n}=8$. The expression level of each gene was calculated using the $\Delta \mathrm{Ct}$ method. To find significant differences, the values were assessed with Student's t-test using SPSS v. 18.0 software (SPSS Inc., Chicago, USA). A p-value $<0.05$ was considered to indicate statistically significant differences between means.

\section{Results}

\section{Observation of cell morphology}

After $24 \mathrm{~h}$ in primary culture, spindle-shaped or polygonal cells were scattered and occasionally reached confluence as observed using phase-contrast microscopy. Further, 7-10 days later, the cells showed a cobblestonelike appearance reaching confluence, basically covering the dish bottom (Fig. 2B) The cells grew densely, and the fused cells were in a swirl shape. The morphology of passaged cells was slightly different from that of primary cells as the former were mostly spindle-shaped, polygonal or branched (Fig. 2C). After $6 \mathrm{~h}$ of treatment with $0.1 \mathrm{mg} / \mathrm{mL}$ of hydrocortisone, cells in the experimental group showed shrinkage and were thus smaller than those in the control group. After 12-24 h, the cells showed growth inhibition, poor state and decreased cell density (Fig. 2D). However, most cells showed apoptosis after $0.3 \mathrm{mg} / \mathrm{mL}$ of hydrocortisone treatment (Fig. 2E). The cells in the control group grew well and gradually fused (Fig. 2F). Therefore, we chose $0.1 \mathrm{mg} / \mathrm{mL}$ hydrocortisone-treated cells for mRNA chip detection.

\section{Endothelial cell characterization}

Primarily, endothelial cells are observed and characterized based on the morphology observed under a phasecontrast microscope, wherein endothelial cells were confirmed by identifying the cobblestone morphology. The expression of several endothelial cell-specific markers, such as vWF (Fig. 2G), CD31 (Fig. 2H) and VE-cadherin (Fig. 2I), was confirmed using immunocytochemistry analysis. Corresponding to Hoechst 33342 cell nuclear staining, immunofluorescence staining revealed that the cells were $100 \%$ positive for vWF and CD31, and near $100 \%$ positive for VE-cadherin. The cells in the negative control group were not stained, showing that the cells cultured were BMECs.

\section{mRNA microarray gene screening results}

Compared with the control group, 519 genes were differentially expressed in BMECs of the experimental group, of which 337 genes were upregulated and 182 genes downregulated. These genes include vasoactive substances synthesized by BMECs, coagulation and fibrinolytic cytokines, and their related receptors. In addition, these are genes that affect cell apoptosis, angiogenesis, cell signal transduction, protein processing, and cell cycle regulation. Among these, 12 genes were associated with endothelial cell function (Table 1).

\section{qPCR results}

According to the results of mRNA chip detection, we selected the genes of ICAM-1, eNOS, ET-1, ET-1 receptor, $\mathrm{PGI}_{2}$ synthase, PAI-1,VEGF, AII receptor, prostaglandin E (PGE) synthase, and PGE receptor for qPCR verification (primer sequence: see Table 2). The relative mRNA expression of ICAM-1, ET-1 receptor, PAI-1, and AII receptor in BMECs of the experimental group was significantly increased compared with the control group, whereas eNOS, ET-1, $\mathrm{PGI}_{2}$ synthase, VEGF, PGE synthase, and PGE receptor expression were significantly decreased (Fig. 3A-J). The results of qPCR were consistent with those of mRNA chip analysis. 

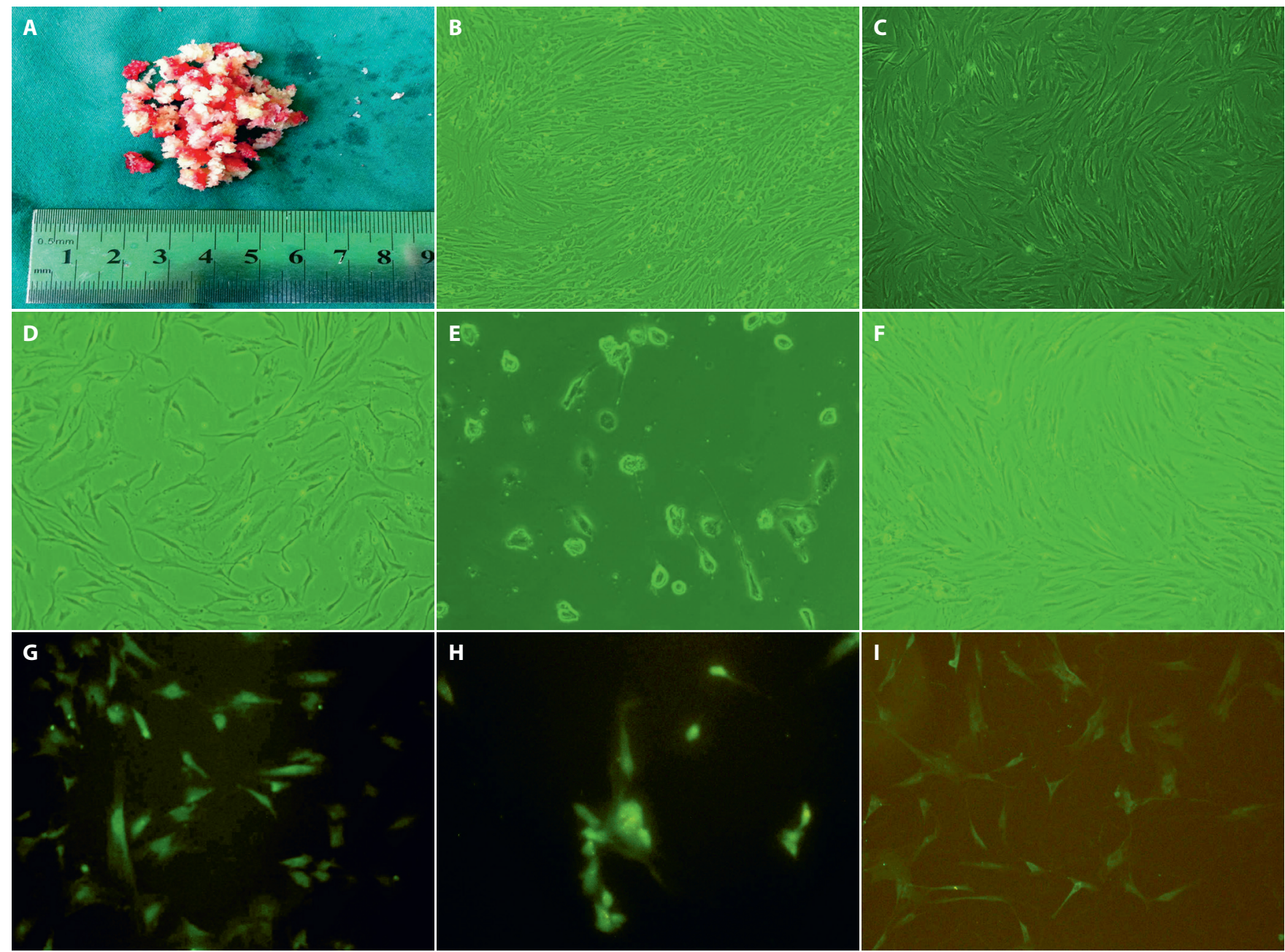

Fig. 2. Isolation and characterization of bone microvascular endothelial cells (BMECs) from human femoral head at $\times 100$ magnification. A. Cancellous granules of the femoral head from patients undergoing total hip arthroplasty (THA) with femoral neck fracture. B. BMECs at P0 form confluent monolayers showing cobblestone morphology. C. BMECs at P3 with mostly fusiform, polygonal and branched cell morphology. D. After $24 \mathrm{~h}$ of $0.1 \mathrm{mg} / \mathrm{mL}$ hydrocortisone treatment, the cell growth condition was poor and the density decreased. E. After $24 \mathrm{~h}$ of $0.3 \mathrm{mg} / \mathrm{mL}$ hydrocortisone treatment, most cells showed apoptosis. F. Cells in the control group developed properly. G. Positively immunostained BMECs using rabbit anti-human von Willebrand factor (vWF). H. Positively immunostained BMECs using rabbit anti-human CD31. I. Positively immunostained BMECs using rabbit anti-human VE-cadherin

Table 1. Differentially expressed genes in femoral head BMECs experimental group and control group

\begin{tabular}{|l|c|c|c|c|}
\hline Genbank accession & Ratio & Gene name & Regulation & p-value \\
\hline NM_001955 & $-1.24 \pm 0.55$ & ET-1 & down & 0.002 \\
\hline NM_001256283 & $2.34 \pm 1.17$ & ET-1 receptor & up & 0.009 \\
\hline NM_000961 & $-0.55 \pm 0.47$ & PGI 2 synthase & down & 0.012 \\
\hline NM_000966 & $-0.40 \pm 0.32$ & PGI 2 receptor & down & 0.044 \\
\hline NM_001287044 & $-0.75 \pm 0.26$ & VEGF A & down & 0.003 \\
\hline NM_005429 & $-0.30 \pm 0.42$ & VEGF C & down & 0.007 \\
\hline NM_000686 & $0.44 \pm 0.23$ & All receptor & up & 0.011 \\
\hline NM_004878 & $-0.84 \pm 0.45$ & PGE synthase & down & 0.012 \\
\hline NM_000956 & $1.37 \pm 0.71$ & PGE receptor & down & 0.010 \\
\hline NM_001160111 & $-0.24 \pm 0.19$ & eNOS & down & 0.042 \\
\hline NM_000201 & $0.52 \pm 0.39$ & ICAM-1 & up & 0.037 \\
\hline NM_000602 & $0.13 \pm 0.03$ & PAI-1 & up & 0.003 \\
\hline
\end{tabular}

eNOS - endothelial nitric oxide synthase; $P G l_{2}$ - prostaglandin $\mathrm{I}_{2}$ ET - endothelin; ICAM-1 - intercellular adhesion molecule 1; VEGF - vascular endothelial growth factor; All - angiotensin II; PAI-1 - plasminogen activator inhibitor 1.

\section{Discussion}

Non-traumatic femoral head necrosis is a common disease. There were 8.12 million patients with this disease in China in 2013. ${ }^{25}$ Steroid-induced ONFH accounts for $30-50 \%$ of all non-traumatic ONFH cases, ${ }^{26}$ and thus far, its pathogenesis is not clear. However, there has been increasing evidence confirming intraosseous microvascular endothelial cell injury and microvascular thrombosis as the pathogenesis of ONFH..$^{18,27,28}$ The microcirculatory vessels in the deep femoral head are mainly irregular sinusoidal capillaries, and the endothelial cells in these structures are characterized by fenestration, large gaps and no septa. The basement membrane of the bone microvessels was incomplete, absent or intermittent, thus facilitating the passage of mature red blood cells. ${ }^{29,30}$ Yang et al. ${ }^{18}$ reported that hydrocortisone at a concentration $>0.1 \mathrm{mg} / \mathrm{mL}$ could cause different degrees of damage and even 
apoptosis to BMECs of the femoral head cultured in vitro. The degree of cell damage was directly proportional to the concentration of hydrocortisone, and the cells died at the concentration of $1 \mathrm{mg} / \mathrm{mL}$. Reportedly, hydrocortisone concentration of $0.1-0.3 \mathrm{mg} / \mathrm{mL}$ is the most suitable concentration of corticosteroids for establishing a GC-damaged BMEC model. On the basis of this study, we also established a model of GC-induced BMEC damage in vitro and screened differentially expressed genes using microarray analysis to detect the mRNA of the cell model. We found that some genes related to endothelial cell function, such as ET-1, ET-1 receptor, ICAM-1, $\mathrm{PGI}_{2}$ synthase,
A

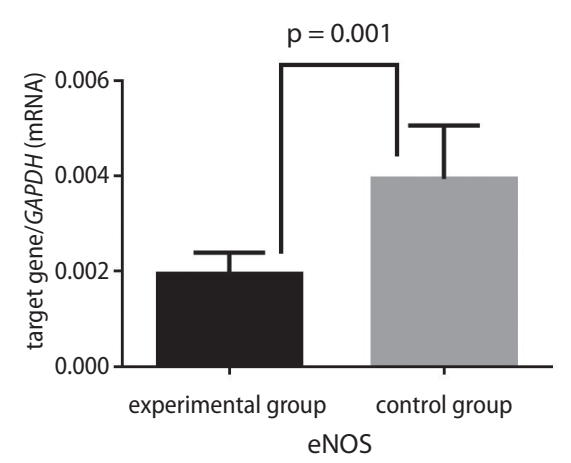

D

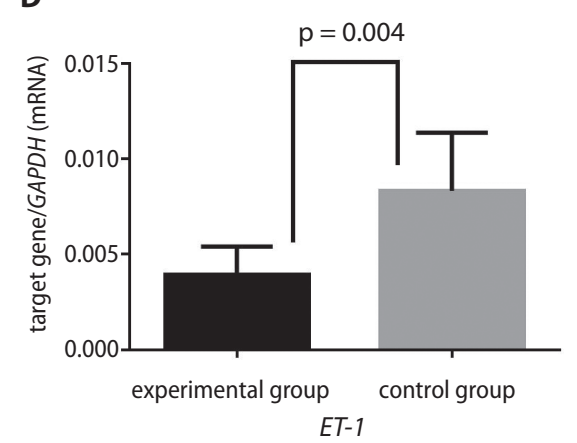

$\mathbf{G}$

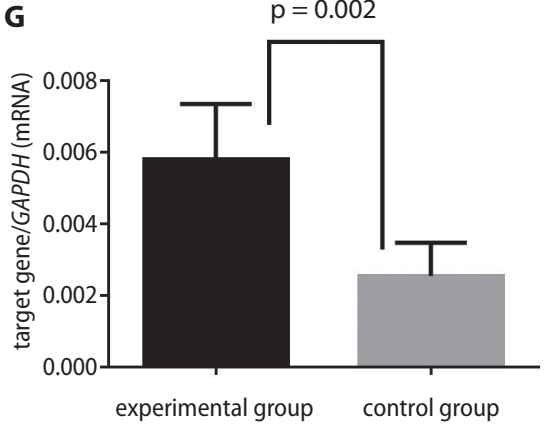

PAl-1

J

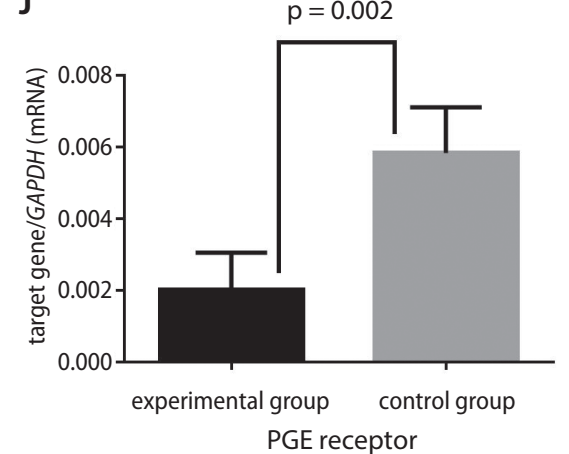

B

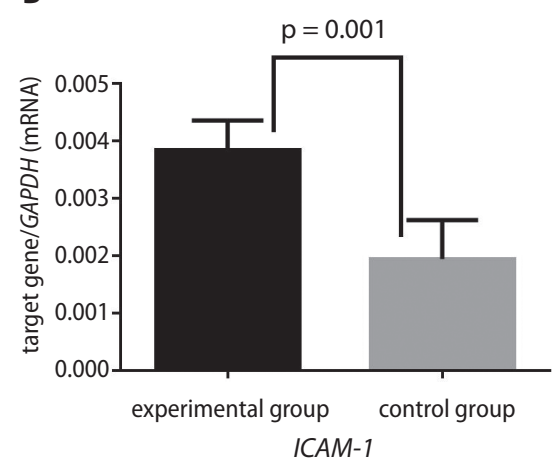

E

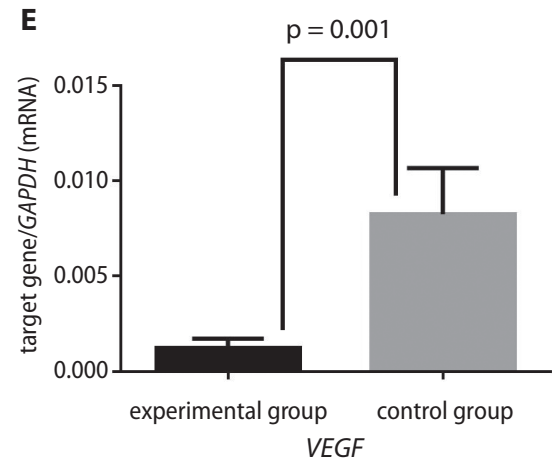

H
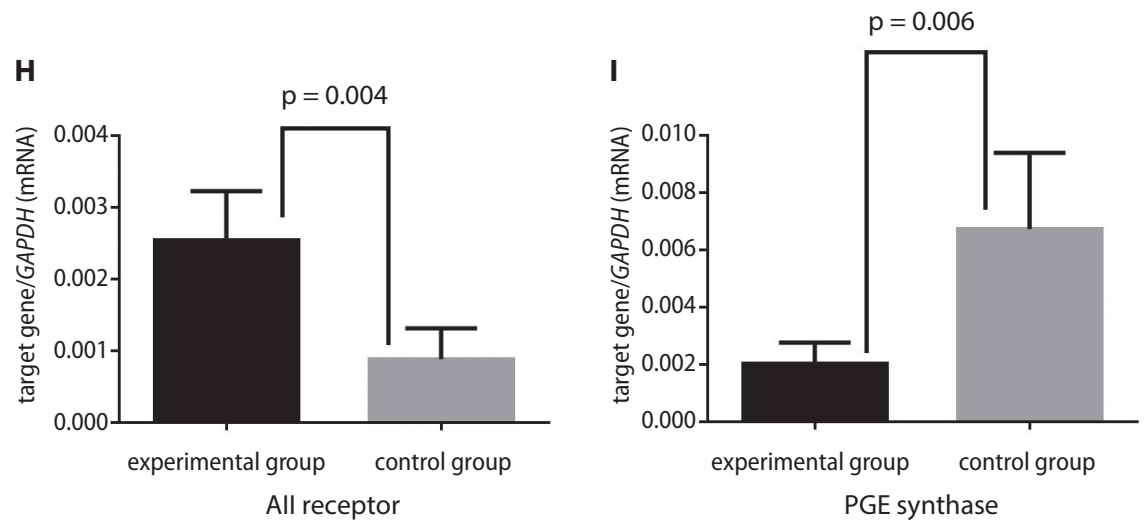

$\mathbf{F}$
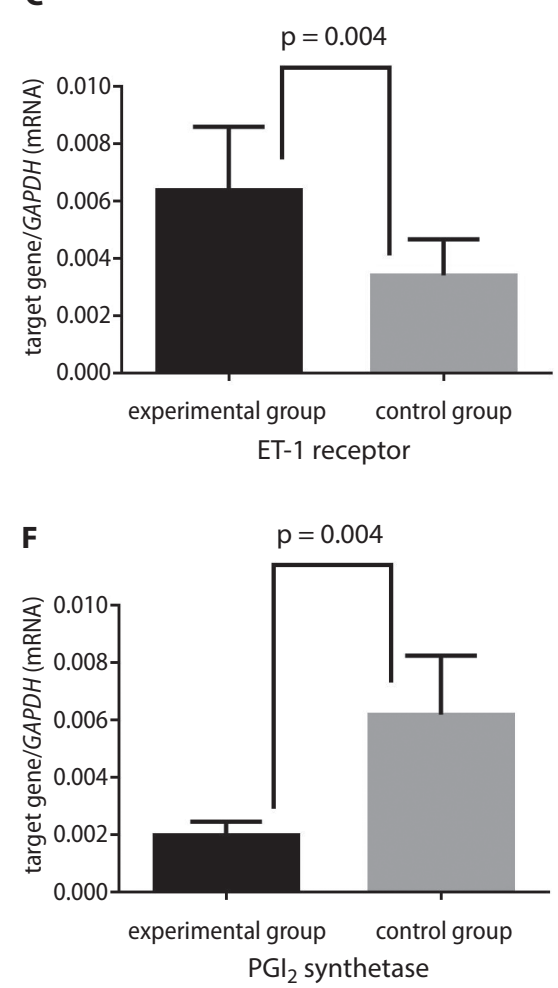

Fig. 3A-J. mRNA expression of eNOS, ICAM-1, ET-1, ET-1 receptor, PGI 2 synthase, VEGF, PAI-1, All receptor, PGE synthase, and PGE receptor in the experimental group as compared with the control group 
Table 2. Primer sequences of target genes and housekeeping genes

\begin{tabular}{|c|c|c|}
\hline \multirow{2}{*}{ Gene } & \multicolumn{2}{|c|}{ Primer } \\
\hline & forward & reverse \\
\hline ICAM-1 & 5'-AGCTTCGTGTCCTGTATGGC-3' & 5'-GACACTTGAGCTCGGGCAAT-3' \\
\hline eNOS & 5'-ACCGGCATCACCAGGAAGA-3' & 5'-TTGTCGCCTTCACTCGCTTC-3' \\
\hline$E T-1$ & 5'-GAGCTCCAGAAACAGCAGTCTTA-3' & 5'-CTTTATCCATCAGGGACGAGCA-3' \\
\hline ET-1 receptor & 5'-TCACTCCCACACCCAAGAAG-3' & 5'-AGTGCTGAATACAACACGCAG-3' \\
\hline $\mathrm{PGl}_{2}$ synthase & 5'-CTGCTCCCAATTCACCTCGT-3' & 5'-CGGGCCATGCTAGCTCATAA-3' \\
\hline PAl-1 & 5'-TTGCAGGATGGAACTACGGG-3' & 5'-GTGGCAGGCAGTACAAGAGT-3' \\
\hline VEGF & 5'-GGGAGCTTCAGGACATTGCT-3' & 5'-GGCAACTCAGAAGCAGGTGA-3' \\
\hline All receptor & 5'-GCCTGTTTGTCCTCATTGCC-3' & 5'-CCAGCTGACCATTGGGCATA-3' \\
\hline PGE synthase & 5'-CCTCCCAAGGTTTGAGTCCC-3' & 5'-AGGGGACATTTGCAGTTTCCA-3' \\
\hline PGE receptor & 5'-CCTTGGGTCTTTGCCATCCT-3' & 5'-GACCTCAAAGGTCAGCCTGT-3' \\
\hline GAPDH & 5'-TGTTGCCATCAATGACCCCTT-3' & 5'-CTCCACGACGTACTCAGCG-3' \\
\hline
\end{tabular}

eNOS - endothelial nitric oxide synthase; $\mathrm{PGI}_{2}$ - prostaglandin $\mathrm{I}_{2} ; \mathrm{PGE}$ - prostaglandin $\mathrm{E}$; ET - endothelin; ICAM-1 - intercellular adhesion molecule 1; VEGF - vascular endothelial growth factor; All - angiotensin II; PAI-1 - plasminogen activator inhibitor 1.

$\mathrm{PGI}_{2}$ receptor, eNOS, VEGF, AII receptor, PAI-1, PGE synthase, and PGE receptor, were significantly changed. The results of qPCR verification of changed gene expressions were consistent with microarray results, indicating a certain relationship between GC-induced ONFH and expression changes of these genes.

Endothelial nitric oxide synthase and ET-1 are 2 vasoactive factors secreted by vascular endothelial cells and have opposite effects. An imbalance between them leads to damaged endothelial cell function. Endothelial cells synthesize and release ET-1, which is the strongest known vasoconstrictor factor. Endothelin 1 binds to the receptors on its endothelial cells and vascular smooth muscles in the bone, and exerts a strong vasoconstrictive effect, thus reducing intraosseous blood flow. A study by Drescher et al. ${ }^{31}$ showed that ET-1 enhanced the contractile effect of the intraosseous artery in the femoral head in vitro in pigs treated with glucocorticoids; however, other vasoactive substances, such as norepinephrine, substance $P$ and bradykinin, exerted no such effect. Endothelial nitric oxide synthase is an endothelial-derived vasodilator primarily synthesized by eNOS in endothelial cells. Endothelial nitric oxide synthase can inhibit the secretion of endothelin and antagonize its effect on vasoconstriction. In addition, eNOS has several anticoagulant actions, such as blood vessel dilatation, platelet aggregation prevention and monocyte-endothelium adherence inhibition. Therefore, the GC-induced decrease in the bioavailability of eNOS elicits vascular endothelial dysfunction, thus causing insufficient peripheral circulation, which is a potential mechanism for GC-induced ON. Angiotensin I (AI) conversion to AII occurs through the removal of 2 C-terminal residues by angiotensin-converting enzyme. Angiotensin II can damage endothelial cells by binding to its receptors on endothelial cells. In addition, it can inhibit eNOS expression and stimulate ROS production by NADP/NADPH oxidase in smooth muscle cells. ${ }^{32}$ Furthermore, research has shown that vasoconstrictor enhancement (e.g., AII) and eNOS synthesis reduction damaged endothelial cells and further reduced blood supply to tissues. ${ }^{33}$ Both $\mathrm{PGI}_{2}$ and $\mathrm{TXA}_{2}$ are important members of the prostaglandin family. Prostaglandin $\mathrm{I}_{2}$ is produced by $\mathrm{PGI}_{2}$ synthase in endothelial cells; it strongly dilates blood vessels and inhibits platelet aggregation by stimulating IP receptors in vascular endothelial cells and platelets. TXA 2 is produced by platelets and causes vasoconstriction and platelet aggregation by activating thromboxane (TP) receptors in vascular endothelial cells and platelets. Both $\mathrm{PGI}_{2}$ and $\mathrm{TXA}_{2}$ are dynamically balanced under physiological conditions. This imbalance plays an important role in the occurrence of vascular diseases. 6-ketone prostaglandin F $\alpha$ (6-keto-PGF $1 \alpha$ ), a $\mathrm{PGI}_{2}$ metabolite, is considered an endothelial cell injury marker. He et al. ${ }^{34}$ reported that when compared to controls, the level of 6-keto-PGF1 $\alpha$ significantly decreased in a rabbit ON model induced by endotoxin and GC. This suggests that $\mathrm{ON}$ presents with another endothelial cell impairment, which is likely to be GC-mediated. The PGE has the function of dilating blood vessels, increasing the blood flow to organs and reducing the resistance of peripheral blood vessels. A research study ${ }^{35}$ has found that PGE protects endothelial cells and upregulates eNOS mRNA and protein expression. The results of our study suggested that the expressions of ET-1 receptor and AII receptor were significantly upregulated, and the expressions of eNOS, $\mathrm{PGI}_{2}$ synthase, PGE synthase, and PGE receptor were significantly downregulated after 24-hour GC treatment. The results showed that the vasoconstriction effect is enhanced, whereas the vasodilator effect is decreased after the GC-induced damage to BMECs. In addition, the effect on endothelial cell injury and the factors promoting thrombosis was strengthened, whereas the protective 
function of endothelial cells was decreased. Therefore, a vicious circle has been formed regarding the damage of endothelial cells. Interestingly, our study showed that ET-1 expression was significantly reduced, suggesting that the effects of GC on BMECs damage and function were exerted via a complex process. PAI-1 is a major inhibitor of plasma t-PA. Abnormal expression of PAI-1 is instrumental in the formation of atherosclerosis. PAI-1 is mainly produced by vascular endothelial cells. Increased expression of PAI-1 promotes the formation of not only intravascular thrombosis but also atherosclerotic plaques. Zeng et al. ${ }^{36}$ performed a meta-analysis, identified 5 articles that met the criteria for review and concluded that there was an association between $P A I-1$ gene $4 \mathrm{G} / 5$ G polymorphism and increased susceptibility to ONFH. Yamamoto et al. ${ }^{37}$ showed that dexamethasone could upregulate the expression of $P A I-1$ gene in human umbilical vein endothelial cells, and they also pointed out that PAI-1 could promote coagulation in both dexamethasone exposure and tumor necrosis factor $\alpha$ (TNF- $\alpha$ ) stimulation. A study by Kim et al. ${ }^{38}$ suggested that $\mathrm{ON}$ was associated with a decrease in fibrinolytic activity induced by increased $P A I-1$ expression. This is in agreement with our current results. Intercellular adhesion molecule 1, a protein also known as cluster of differentiation 54, is encoded in humans by the ICAM-1 gene. This gene codes for a cell surface glycoprotein that is typically expressed on endothelial cells. Intercellular adhesion molecule 1 , an important adhesion molecule, mediates the adhesion reaction. It is expressed at low levels in resting vascular endothelial cells, and the intercellular adhesion mediated by it plays a role in many aspects of the immune response. It enhances the adhesion between leukocytes, inflammatory cells and endothelial cells, promotes the activation of endothelial cells and makes it easier for them to penetrate the endothelium. A study by Lawson and Wolf ${ }^{39}$ showed that with the increase in ICAM-1 expression of endothelial cells, atherosclerosis became more severe. A high dose of GCs can damage BMECs, increase the expression of ICAM-1 and promote the formation of microcirculatory thrombosis, which may be an important factor in the pathogenesis of steroid-induced femoral head necrosis. Vascular endothelial growth factor acts directly on vascular endothelial cells and induces angiogenesis. A research study by Li et al. ${ }^{40}$ showed that high-dose GCs can reduce VEGF synthesis in bone marrow progenitor cells. Vascular endothelial cells can also produce VEGF. Our study showed that a high dose of GCs decreased the expression of $V E G F$ in BMECs, but did not affect the expression of the VEGF receptor.

There were several limitations in our study. Firstly, the BMECs examined in this study were from the elderly (>60 years), while most patients with GC-induced ONFH are young. With the increase of age, the function of the BMECs may weaken and the results might differ as well; therefore, selection bias existed in the study. Secondly, our sample size was small. Only 8 patients were selected as the study population. It is necessary to select more patients in a multicenter study to increase the accuracy of the study. Thirdly, this is an in vitro study. The effect of GCs on bones in vivo is much more complex than in vitro, and the disease-producing dose of GCs is also different.

In conclusion, our study found that GCs promoted the expression of vasoconstrictors, procoagulant factors and the related receptors secreted by BMECs, and decreased the expression of vasodilator and corresponding receptors. Therefore, it can be deduced that complex functional changes happen after GC damage to BMECs, resulting in intraosseous microvascular thrombosis, microcirculation failure, and ultimately bone tissue ischemia and necrosis.

\section{ORCID iDs}

Yufeng Lu (1) https://orcid.org/0000-0003-4527-0760

Qingsheng Yu (1) https://orcid.org/0000-0003-0870-884X Wanshou Guo (i) https://orcid.org/0000-0002-6830-3521 Yangquan Hao (1) https://orcid.org/0000-0002-0488-5884 Wei Sun (1) https://orcid.org/0000-0002-9805-8491

Liming Cheng (1) https://orcid.org/0000-0003-0790-3758

\section{References}

1. Mont M, Pivec R, Banerjee S, Issa K, Elmallah RK, Jones LC. High-dose corticosteroid use and risk of hip osteonecrosis: Meta-analysis and systematic literature review. J Arthroplasty. 2015;30(9):1506-1512.

2. Wang Y, Li Y, Mao K, Li J, Cui Q, Wang GJ. Alcohol-induced adipogenesis in bone and marrow: A possible mechanism for osteonecrosis. Clin Orthop Relat Res. 2003;410:213-224.

3. Sharareh B, Schwarzkopf R. Dysbaric osteonecrosis: A literature review of pathophysiology, clinical presentation, and management. Clin J Sport Med. 2015;25(2):153-161.

4. Milner PF, Kraus AP, Sebes Jl, et al. Sickle cell disease as a cause of osteonecrosis of the femoral head. N Engl J Med. 1991;325(21):1476-1481.

5. Nakamura J, Konno K, Orita S, et al. Distribution of hip pain in patients with idiopathic osteonecrosis of the femoral head. Mod Rheumatol. 2017;27(3):503-507.

6. Kobayashi S, Kubo T, Iwamoto Y, Fukushima W, Sugano N. Nationwide multicenter follow-up cohort study of hip arthroplasties performed for osteonecrosis of the femoral head. Int Orthop. 2018;42(7): 1661-1668.

7. Ikeuchi K, Hasegawa Y, Seki T, Takegami Y, Amano T, Ishiguro N. Epidemiology of nontraumatic osteonecrosis of the femoral head in Japan. Mod Rheumatol. 2015;25(2):278-281.

8. Fukushima W, Fujioka M, Kubo T, Tamakoshi A, Nagai M, Hirota Y, Nationwide epidemiologic survey of idiopathic osteonecrosis of the femoral head. Clin Orthop Relat Res. 2010;468(10):2715-2724.

9. Kang JS, Park S, Song JH, Jung YY, Cho MR, Rhyu KH. Prevalence of osteonecrosis of the femoral head: A nationwide epidemiologic analysis in Korea. J Arthroplasty. 2009;24(8):1178-1183.

10. Youm YS, Lee SY, Lee SH. Apoptosis in the osteonecrosis of the femoral head. Clin Orthop Surg. 2010;2(4):250-255.

11. Mutijima E, De Maertelaer V, Deprez M, Malaise M, Hauzeur JP. The apoptosis of osteoblasts and osteocytes in femoral head osteonecrosis: Its specificity and its distribution. Clin Rheumatol. 2014; 33(12):1791-1795.

12. Ren X, Fan W, Shao Z, Chen K, Yu XX, Liang Q. A metabolomic study on early detection of steroid-induced avascular necrosis of the femoral head. Oncotarget. 2018;9(8):7984-7995.

13. Zhang Q, L V J, Jin L. Role of coagulopathy in glucocorticoid-induced osteonecrosis of the femoral head. JInt Med Res. 2018;46(6):2141-2148.

14. Akaike M, Matsumoto T. Glucocorticoid-induced reduction in NO bioavailability and vascular endothelial dysfunction. Clin Calcium. 2007;17(6):864-870. 
15. Kerachian MA, Séguin C, Harvey EJ. Glucocorticoids in osteonecrosis of the femoral head: A new understanding of the mechanisms of action. J Steroid Biochem Mol Biol. 2009;114(3-5):121-128.

16. Vogt CJ, Schmid-Schönbein GW. Microvascular endothelial cell death and rarefaction in the glucocorticoid-induced hypertensive rat. Microcirculation. 2001;8(2):129-139.

17. Li Y, Chen J, Zhang Z, Wang K, Tong Z, Yan H. The experimental study on treatment of glucocorticoid-induced ischemic necrosis of femoral head by Gu Fu Sheng capsule. J Tradit Chin Med. 2004;24(4):303-307.

18. Yang Y, Lou J, Li Z, Sun W, Wang B, Jia Y. Effect of glucocorticoid on production of reactive oxygen species in bone microvascular endothelial cells [in Chinese]. Zhongguo Xiu Fu Chong Jian Wai Ke Za Zhi. 2011;25(5):533-537.

19. Wnuczko K, Szczepański M. Endothelium: Characteristics and functions [in Polish]. Pol Merkur Lekarski. 2007;23(133):60-65.

20. Van Veldhuizen PJ, Neff J, Murphey MD, Bodensteiner D, Skikne BS Decreased fibrinolytic potential in patients with idiopathic avascular necrosis and transient osteoporosis of the hip. Am J Hematol. 1993;44(4):243-248.

21. Glueck CJ, Glueck HI, Mieczkowski L, Tracy T, Speirs J, Stroop D. Familial high plasminogen activator inhibitor with hypofibrinolysis: A new pathophysiologic cause of osteonecrosis? Thromb Haemost. 1993; 69(5):460-465.

22. Asano T, Takahashi KA, Fujioka M, et al. Relationship between postrenal transplant osteonecrosis of the femoral head and gene polymorphisms related to the coagulation and fibrinolytic systems in Japanese subjects. Transplantation. 2004;77(2):220-225.

23. Yu Q, Guo W, Cheng L, Lu Y, Li P. Preliminary study of impact of steroids on expression profile and transcriptome of bone microvascular endothelial cells [in Chinese]. Zhonghua Yi Xue Za Zhi. 2014;94(48): 3817-3820.

24. Lu YF, Yu QS, Guo WS, Cheng LM, Zhang Y. A method for isolated culture of bone microvascular endothelial cells of human femoral head [in Chinese]. Zhongguo Gu Shang. 2014;27(10):843-847.

25. Microsurgery Department of the Orthopedics Branch of the Chinese Medical Doctor Association; Group from the Osteonecrosis and Bone Defect Branch of the Chinese Association of Reparative and Reconstructive Surgery; Microsurgery and Reconstructive Surgery Group of the Orthopedics Branch of the Chinese Medical Association; et al. Chinese Guideline for the Diagnosis and Treatment of Osteonecrosis of the Femoral Head in Adults. Orthop Surg. 2017;9(1):3-12.

26. Youm YS, Lee SY, Lee SH. Apoptosis in the osteonecrosis of the femoral head. Clin Orthop Surg. 2010;2(4):250-255.
27. Chotanaphuti T, Heebthamai D, Chuwong M, KanchanaroekK. The prevalence of thrombophilia in idiopathic osteonecrosis of the hip. J Med Assoc Thai. 2009;92(Suppl 6):S141-146.

28. Zalavras CG, Vartholomatos G, Dokou E, Malizos KN. Genetic background of osteonecrosis: Associated with thrombophilic mutations? Clin Orthop Relat Res. 2004;422:251-255.

29. De Bruyn PP. Structural substrates of bone marrow function. Semin Hematol. 1981;18(3):179-193.

30. Tavassoli M. The marrow-blood barrier. Br J Haematol. 1979;41(3): 297-302.

31. Drescher W, Li H, Lundgaard A, Bünger C, Hansen ES. Endothelin1 -induced femoral head epiphyseal artery constriction is enhanced by long-term corticosteroid treatment. J Bone Joint Surg Am. 2006;88 (Suppl 3):173-179.

32. Shatanawi A, Lemtalsi T, Yao L, Patel C, Caldwell RB, Caldwell RW. Angiotensin II limits NO production by upregulating arginase through a p38 MAPK-ATF-2 pathway. Eur J Pharmacol. 2015;746:106-114.

33. Montezano AC, Nguyen Dinh Cat A, Rios FJ, Touyz RM. Angiotensin II and vascular injury. Curr Hypertens Rep. 2014;16(6):431.

34. He W, Xu C, Fan Y, et al. Effects of the Chinese drugs for activating blood circulation on plasma TXB2 and 6-keto-PGF1alpha contents in rabbits with glucocorticoid-induced femoral head necrosis. J Tradit Chin Med. 2004;24(3):233-237.

35. Fang WT, Li HJ, Zhou LS. Protective effects of prostaglandin $E_{1}$ on human umbilical vein endothelial cell injury induced by hydrogen peroxide. Acta Pharmacol Sin. 2010;31(4):485-492.

36. Zeng Z, Wang B, Pan H. Relation between osteonecrosis of the femoral head and PAI-1 4G/5G gene polymorphism: A meta-analysis. A Int J Clin Exp Med. 2015;8(11):20337-20342.

37. Yamamoto $Y$, Ishizu A, Ikeda H, Otsuka N, Yoshiki T. Dexamethasone increased plasminogen activator inhibitor-1 expression on human umbilical vein endothelial cells: An additive effect to tumor necrosis factor-alpha. Pathobiology. 2004;71(6):295-301.

38. Kim H, Cho C, Cho Y, Cho S, Yoon K, Kim K. Significant associations of PAl-1 genetic polymorphisms with osteonecrosis of the femoral head. BMC Musculoskelet Disord. 2011;12:160.

39. Lawson C, Wolf S. ICAM-1 signaling in endothelial cells. Pharmacol Rep. 2009;61(1):22-32.

40. Li X, Jin L, Cui Q, Wang GJ, Balian G. Steroid effects on osteogenesis through mesenchymal cell gene expression. Osteoporos Int. 2005; 16(1):101-108. 